\title{
Increased Productivity in Dairy Farming in Araguaia Design Municipality - PA
}

\author{
Ricardo Alencar Libório ${ }^{1 *}$, Elika Oliveira Moreira² ${ }^{2}$ Adeivo da Silva Dias ${ }^{2}$ and Jonailton Souza Silva ${ }^{2}$ \\ ${ }^{1}$ IFTO Teacher, Brazil \\ ${ }^{2}$ Agricultural technicians - IFPA - Conceição do Araguaia Campus, Brazil \\ *Corresponding author: Ricardo Alencar Libório, IFTO Teacher, Brazil

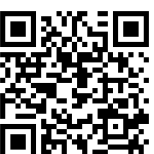

\section{ARTICLE INFO}

Received: 㓞 December 04, 2019

Published: 幽 December 11, 2019

Citation: Ricardo Alencar Libório, Elika Oliveira Moreira, Adeivo da Silva Dias, Jonailton Souza Silva. Increased Productivity in Dairy Farming in Araguaia Design Municipality - PA. Biomed J Sci \& Tech Res 23(5)2019. BJSTR. MS.ID.003958.

Keywords: Somatotropin; Production; Development

\section{ABSTRACT}

Milk production in Brazil has been increasingly an important economic sector investment because they return the same result. This research is an analysis of milk production using modern biotechnology, in a study of recombinant bovine somatotropin, a natural hormone capable of significantly increasing the amount of milk produced. In the 1990s, the production of recombinant somatotropin has allowed the development of several processes, including its production on an industrial scale. Enabling its diffusion in the market today. Thus, during the investigation, the objective of increasing milk production using this hormone was a success.

\section{Summary}

In Brazil, dairy farming has been increasingly seen as a sector of large investments, due to the economic return from it. This research analyzes the increase of milk production through the use of modern biotechnologies, in a study of recombinant bovine Somatotropin, a natural hormone capable of significantly increasing the amount of milk produced. In the early nineties the production of recombinant Somatotropin made possible the development of various processes, including its production on an industrial scale. Which made possible its diffusion in the market today. Thus, during the research, the goal of increasing milk production using this hormone was very successful.

\section{Introduction}

In recent decades dairy activity has been a high degree of development in Brazil. This fact has contributed to the investments growth and strengthening of the milk production chain increase significantly. Milkis a natural food known for its excellent nutritional value besides being energetic. Milk contributes to various functions at all ages and is necessary in human food because it is one of the main sources of calcium, and vitamins. In the municipality of conception of Araguaia-PA becomes compensating to dairy farming, where demand is not yet being supplied and the price of liter of milk at points of sale is being well paid to the producer, A property with good productive efficiency, where animals have a good food management, becomes feasible to use bovine somatotropin Recombinant. Somatotropin is a natural hormone, which has an effect on galactopoietic, in addition to performing action in somatic cells, in the metabolism of carbohydrates, proteins and lipids, enabling the significant increase in peak milk production [1].

For the beginning of the 1980s, the use of recombinant somatotropin enabled or development of several processes, including its manufacturing on an industrial scale. Somatotropin was or first medicine paid for use in bovine culture dairy during or during the lactation period, forming a reliable, active and profitable administration tool for the rancher [2]. The somatotropin administration requires the immediate use of existing non-organism energy reserves, and the diminution of the formation of new fat reserves, mobilizing or bodily stiffening and cooperating with the increase of the milk. Animals with negative energy balance should not receive treatment with somatotropin due to the fact of the great nutritional requirement, so if this administration is done the 
producer will have losses, due to the great energy requirement for the use of this biotechnology the cow will not produce satisfactory results.

The product does not cause any damage to the animal and leaves no trace in the milk being suitable for human consumption and production of its derivatives, where its application is made, on average, every 14 days being easy to apply, after guidance of qualified professionals, does not require specialized labor. Besides being a low-cost product it is still very efficient as long as the necessary recommendations are followed for the product to have satisfactory results. This project was carried out in partnership with the company Intervet and its main purpose is to expand the use of technologies applied to the dairy activity with the use of Boostin in this region [3]. The use of technology in dairy activity, such as the use of hormonal supplementation (Boostin), is expected to contribute to increased milk productivity, considering the nutritional conditions of the animal so that there is no damage to the milk or to it. economic damage to the breeder. This work aimed to increase dairy production in properties of the region of Conceição do Araguaia - PA.

\section{Methodology}

This research was conducted in rural properties in the municipality of Conceição do Araguaia - PA, where the property was first evaluated to determine the number of animals in the lactating herd, the calving season of each animal, the average daily production and the nutritional management of the animals, for example, cultivated forage species and type of food supplementation provided (forages, sugar cane with urea) [4]. For the beginning of the production evaluations, a priori lots of animals distributed in 03 properties of the region were evaluated. Hormones (Boostin) will be needed, financial resources to perform this work, as well as vehicle for locomotion and assistance during Boostin applications. Another important factor is the availability of financial incentive scholarships to students, assisting in their vocational training. The aim was to show the farmer the importance of dairy cattle farming, encouraging him to invest in improvements in animal nutrition, giving him a prior knowledge of the benefits you will gain from the use of innovative products on the market, focusing on the use of hormone supplementation with Boostin [5,6].

\section{Results Evaluation}

It was observed that the increase of milk production was satisfactory due to the use of somatotropin (Boostin), being found that this is undoubtedly a very useful tool in dairy farming. However, one should not discard the advice of qualified professionals regarding the use with caution and common sense. It requires an increase in management excellence, especially the animal's nutritional efficiency by directing the cow's ingested nutrients to the mammary gland and maintaining the lactation peak for a period longer than other animals. If the guidelines are not followed correctly the use of this biotechnology can become dangerous. In most recommendations the interval of applications should be every 14 days, but it is found that applications every 10 days are extremely efficient to keep the lactation peak constant. The first application should be done 60 days postpartum or when the cows are in positive energy balance, not to affect animal health. The handling and care of animals must be excellent, thus ensuring a sustainable increase in milk production.

\section{References}

1. AGUIAR APA (2003) Rotational grazing system. In: Paste Management Course. Itapetinga, Sebrae, p. 66-99.

2. Benedetti E (2002) Pasture milk production - practical bases. Salvador, Seagri, pp. 176.

3. Barbosa MAA (2001) Birth JR Pasture management and milk production in pasture.

4. Ponchio LA, Gomes AL, PAZE da (2005) Perspectives of milk consumption in Brazil.

5. Thaler Neto A (2006) Genetic Improvement Applied to Milk Production. Anais, Chapecó.

6. Zoccal R, Souza AD, Gomes AT, Milk JLB (2003) Milk Production in Family Farming.

\section{ISSN: 2574-1241}

DOI: $10.26717 /$ BJSTR.2019.23.003958

Ricardo Alencar Libório. Biomed J Sci \& Tech Res

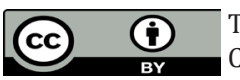

This work is licensed under Creative Commons Attribution 4.0 License

Submission Link: https://biomedres.us/submit-manuscript.php

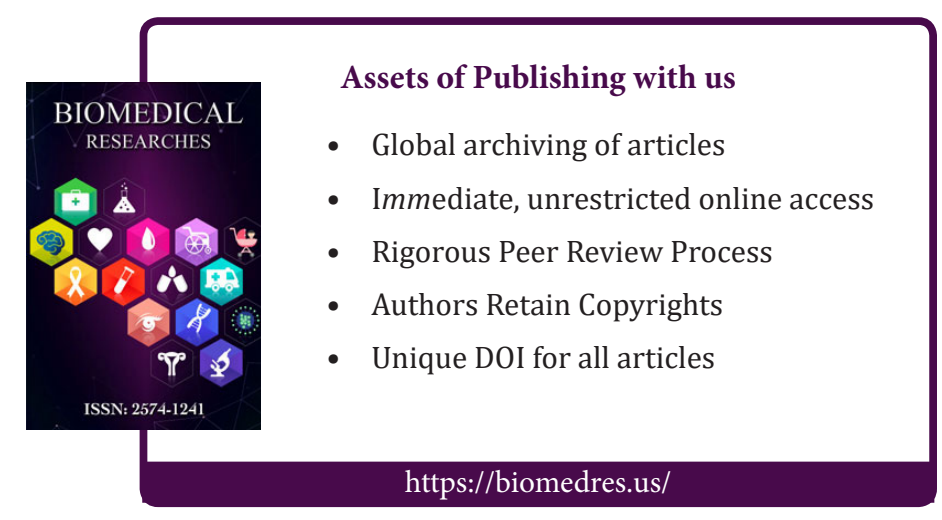

